\title{
Chemical characterization of pitch deposits produced in the manufacturing of high-quality paper pulps from hemp fibers
}

\author{
Ana Gutiérrez *, José C. del Río \\ Instituto de Recursos Naturales y Agrobiología, CSIC, P.O. Box 1052, E-41080 Seville, Spain
}

Received 8 March 2004; received in revised form 30 November 2004; accepted 7 December 2004

Available online 5 February 2005

\begin{abstract}
The composition of pitch deposits occurring in pulp sheets and mill circuits during soda/anthraquinone pulping and elemental chlorine-free pulp bleaching of bast fibers of industrial hemp (Cannabis sativa) was studied. Pitch deposits were extracted with acetone, and the extracts analyzed by gas chromatography (GC) and gas chromatography/mass spectrometry (GC/MS). Acetone extracts (15-25\% of pitch deposits) were constituted by the defoamers used at the mill and by lipophilic extractives from hemp fibers. Acetone-insoluble residues (75-85\% of pitch deposits) were analyzed by pyrolysis-GC/MS in the presence and absence of tetramethylammonium hydroxide. These residues were constituted by salts of fatty acids (arising from hemp fibers) with calcium, magnesium, aluminum and other cations that were identified in the deposits. It was concluded that inappropriate use of defoamer together with the presence of multivalent ions seemed to be among the causes of hemp extractives deposition in the pitch problems reported here. (C) 2005 Elsevier Ltd. All rights reserved.
\end{abstract}

Keywords: Pitch; Extractives; Industrial hemp; Cannabis sativa; Defoamer; Fatty acid salts; Paper pulp; Analytical pyrolysis; Tetramethylammonium hydroxide

\section{Introduction}

It is well known that lipophilic extractives from woody plants cause significant problems in pulp and paper manufacturing industrial processes (Hillis and Sumimoto, 1989; Back and Allen, 2000). They form the so-called "pitch" deposits in mill circuits, equipment and final product. These compounds may deposit alone or with other components such as inorganic salts, defoamers and coating binders present in the pulping and papermaking process. Trends towards a higher degree of system closure in pulping and bleaching plants to fulfill environmental demands are aggravating these problems.

Most information regarding the problem of pitch deposition refers to wood processing (Back and Allen,

\footnotetext{
* Corresponding author. Tel.: +3495462 4711; fax: +34 954624002.

E-mail address: anagu@irnase.csic.es (A. Gutiérrez).
}

2000; Gutiérrez et al., 2001a). However, pitch deposits also occur during the manufacturing of non-wood fiber pulps. An investigation of the composition of pitch deposits produced in paper pulps and mill circuits during manufacturing of "elemental chlorine free" (ECF) alkaline pulps from industrial hemp fibers is described in the present paper. To the best of the authors' knowledge, no previous papers dealing with pitch problems during manufacturing of paper pulp from non-wood materials have been published.

Hemp (Cannabis sativa) is native to central Asia and has been cultivated in Asia and Europe for many years. In Europe, the cultivation of hemp declined in the 19th century but recently interest has been renewed, for example in Germany, France, the Netherlands, the UK, Spain and Italy (Struik et al., 2000). Uses for industrial hemp fibers in the paper industry mainly include specialty papers, e.g. cigarette papers, bible papers and condenser papers (Moore, 1996). To the authors' 
knowledge, there are no previous publications in the literature reporting the chemical composition of lipophilic extractives from industrial hemp fibers. To maximize the exploitation of this fiber for paper pulp production, a more complete understanding of its chemistry is required. In the present work, the composition of lipophilic extractives from industrial hemp fibers used as raw material was investigated to establish the involvement of these compounds in the formation of the pitch deposits reported here.

\section{Methods}

\subsection{Samples}

The pitch deposits selected for this study were supplied by a pulp mill in Tortosa (Spain), which produces high-quality hemp pulp by soda/anthraquinone cooking (Holton, 1977) followed by ECF bleaching with chlorine dioxide, after two severe pitch episodes (A and B) occurred in the mill. One pitch deposit was collected from final bleached pulp after episode A, and the other two deposits were collected from bleached pulp and mill circuits after episode B. Samples of raw material (bast fibers of industrial hemp containing $20 \%$ of core fibers) and of two different defoamers (oil-based) that were used at the mill when the pitch episodes occurred were also supplied by the mill.

The different pitch deposits and the raw material were Soxhlet-extracted with acetone for 24 and $8 \mathrm{~h}$, respectively. The acetone extracts were evaporated to dryness and redissolved in chloroform for analysis of the lipophilic fraction by gas chromatography (GC) and gas chromatography-mass spectrometry (GC/MS). There was no insoluble residue after chloroform dissolution of the acetone extract. Aliquots of the defoamers were diluted in chloroform and analyzed by $\mathrm{GC}$ and $\mathrm{GC} /$ MS. All extracts and defoamers were also analyzed after bis(trimethylsilyl)trifluoroacetamide (BSTFA) silylation. On the other hand, the residues left after acetone extraction were analyzed by Curie-point flashpyrolysis-GC/MS (Py-GC/MS) both in the absence and presence of tetramethylammonium hydroxide (TMAH). The composition of metals from these deposits was analysed by induced coupled plasma-optical emission spectroscopy (ICP-OES).

\section{2. $G C$ and $G C / M S$}

GC analyses were performed in a Hewlett-Packard HP-5890 using a short fused silica capillary column (DB-5HT; $5 \mathrm{~m} \times 0.25 \mathrm{~mm}$ I.D., $0.1 \mu \mathrm{m}$ film thickness) from J\&W Scientific. The temperature program started at $100{ }^{\circ} \mathrm{C}$ with a $1 \mathrm{~min}$ hold, and temperature was then raised to the final value of $350{ }^{\circ} \mathrm{C}$ at $15^{\circ} \mathrm{C} / \mathrm{min}$ and held for $3 \mathrm{~min}$. The injector (split-splitless) and flameionization detector temperatures were set at $300{ }^{\circ} \mathrm{C}$ and $350^{\circ} \mathrm{C}$ respectively. The carrier gas was helium, and injection was performed in splitless mode.

GC/MS analyses were performed in a Varian Saturn 2000 with an ion trap detector, equipped with a fused silica capillary column (DB-5HT, J\&W; $15 \mathrm{~m} \times 0.25 \mathrm{~mm}$ I.D., $0.1 \mu \mathrm{m}$ film thickness). The oven was heated from $120^{\circ} \mathrm{C}(1 \mathrm{~min})$ to $380^{\circ} \mathrm{C}$ at $10^{\circ} \mathrm{C} / \mathrm{min}$ and held for $5 \mathrm{~min}$. The transfer line was kept at $300{ }^{\circ} \mathrm{C}$. The injector was temperature programmed from $120^{\circ} \mathrm{C}(0.1 \mathrm{~min})$ to $380^{\circ} \mathrm{C}$ at a rate of $200{ }^{\circ} \mathrm{C} / \mathrm{min}$ and held until the end of the analysis. Helium was used as carrier gas. Compounds were identified by comparing the mass spectra obtained with those of the Wiley and NIST computer libraries, by mass fragmentography and, when possible, by comparing with authentic standards.

\section{3. $P y-G C / M S$}

Pyrolysis of the acetone insoluble residues was performed with a Curie-point pyrolyser (Horizon instruments) coupled to a Varian Saturn 2000 GC/MS equipment, using a $30 \mathrm{~m} \times 0.25 \mathrm{~mm}$ I.D. DB-5 column (film thickness $0.25 \mu \mathrm{m}$ ) from J\&W Scientific. Approximately $100 \mu \mathrm{g}$ of sample in finely divided form, was deposited on a ferromagnetic wire. The wire was then inserted into the glass liner, which was subsequently placed in the pyrolyser. Pyrolysis was carried out at $610^{\circ} \mathrm{C}$ for $4 \mathrm{~s}$. The chromatograph was programmed from $40{ }^{\circ} \mathrm{C}(1 \mathrm{~min})$ to $300^{\circ} \mathrm{C}$ at a rate of $6{ }^{\circ} \mathrm{C} / \mathrm{min}$. The final temperature was held for $20 \mathrm{~min}$. The injector, equipped with a liquid carbon dioxide cryogenic unit, was programmed from $-30{ }^{\circ} \mathrm{C}(1 \mathrm{~min})$ to $300{ }^{\circ} \mathrm{C}$ at $200^{\circ} \mathrm{C} / \mathrm{min}$, while the $\mathrm{GC} / \mathrm{MS}$ interface was kept at $300^{\circ} \mathrm{C}$.

\section{4. $P y(T M A H)-G C / M S$}

Approximately $100 \mu \mathrm{g}$ of the acetone insoluble residue sample in finely divided form was deposited on a ferromagnetic wire and mixed with approximately $0.5 \mu \mathrm{l}$ of TMAH (25\% w/w aqueous solution). The wire was then inserted into the glass liner, which was subsequently placed in the pyrolyzer. Pyrolysis was carried out as described above.

\section{Results}

\subsection{Analysis of pitch deposits}

The pitch deposits studied here appeared during the manufacturing of high-quality paper pulps from industrial hemp fibers in a mill using alkaline (soda/anthraquinone) pulping and ECF bleaching processes. Deposits 
were constituted by two fractions, an acetone soluble extract (15-25\%) and an acetone insoluble residue (75-85\%). Table 1 shows the relative compositions of both fractions in the different pitch deposits.

The acetone soluble fractions of the pitch deposits were analyzed (before and after silylation with BSTFA) by a gas chromatographic procedure using hightemperature short and medium capillary columns previously developed for the rapid analysis of wood extractives (Gutiérrez et al., 1998). The chromatograms of the underivatized extracts from the selected deposits are shown in Fig. 1. It can be observed that the GC patterns of the three deposits are very similar, with the predominance of a wide, non-resolved peak, common to all deposits, and the presence of small amounts of other compounds. The silylation of samples did not improve the resolution of those non-resolved peaks. Among the other compounds present, a series of fatty alcohols ranging from $\mathrm{C}_{22}$ to $\mathrm{C}_{34}$ (with maxima at $\mathrm{C}_{28}$ and $\mathrm{C}_{30}$ ) and $n$ alkanes, ranging from $\mathrm{C}_{27}$ to $\mathrm{C}_{31}$ (with maximum at $\mathrm{C}_{29}$ ) predominated. A series of fatty acids ranging from $\mathrm{C}_{16}$ to $\mathrm{C}_{24}$, were also identified. Some of these fatty acids, namely $\mathrm{C}_{16}$ and $\mathrm{C}_{18}$, coeluted with the wide, nonresolved peak but they could be identified by monitoring their characteristic fragments in their mass spectra. Minor amounts of 9,10-dihydroxyoctadecanoic acid, an oxidation product of oleic acid, were identified as trimethylsilyl (TMS) derivative. Traces of triterpenols ( $\beta$-amyrin), saturated sterols (stigmastanol) and two oxidized sterols (5,6-epoxy-stigmastan-3-ol and 3hydroxy-stigmastane-6-one) identified as TMS derivatives, were also found in the pitch deposit extracts.

On the other hand, the acetone insoluble residues of pitch deposits were analyzed by $\mathrm{Py}-\mathrm{GC} / \mathrm{MS}$ (data not shown) and released a series of $n$-alkanes $/ n$-alkenes from $\mathrm{C}_{8}$ to $\mathrm{C}_{28}$ indicating the organic and highly aliphatic character of the residue. However, no further structural information could be obtained from the pyrolysis data due to the inherent limitations of the technique such as decarboxylation of carboxylic moieties (del Río et al., 1998). Some of these analytical limitations can be overcome by pyrolysis in the presence of a methylating reagent (TMAH). Pyrolysis (TMAH), also called simultaneous pyrolysis-methylation, protects carboxyl
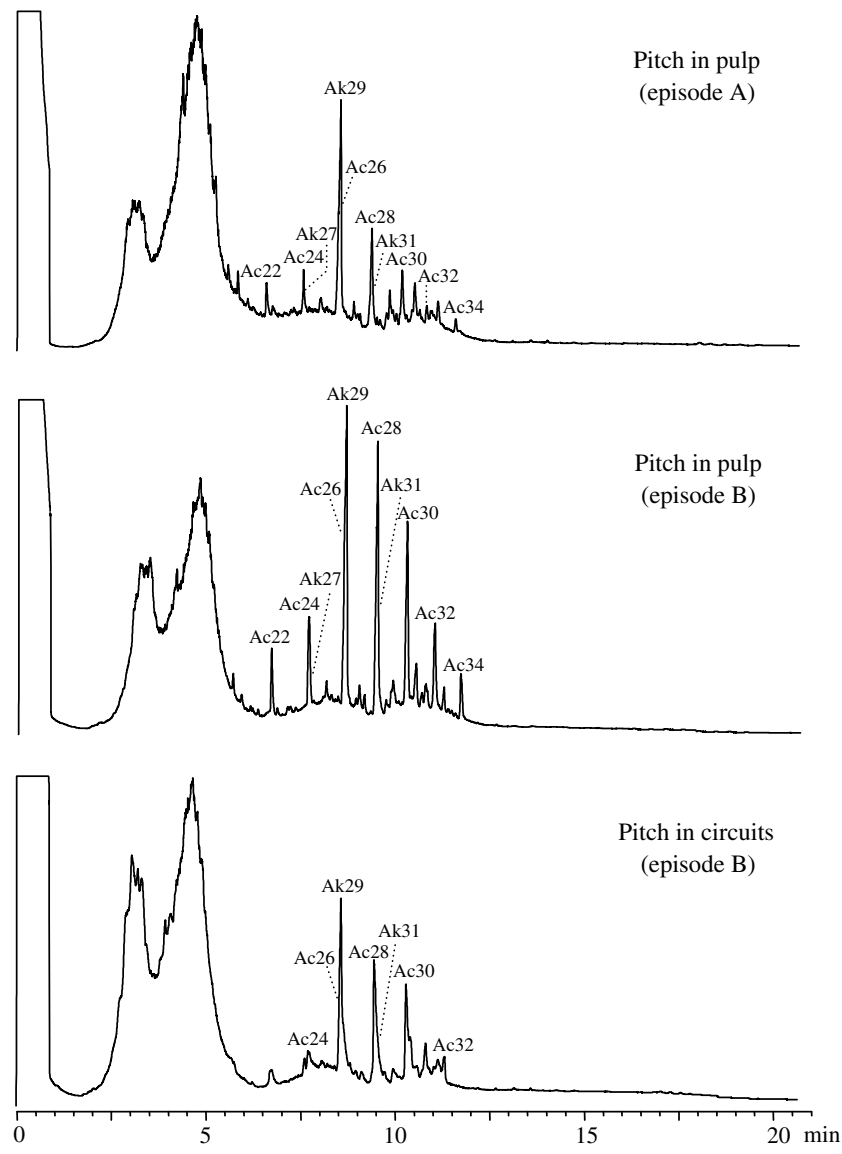

Fig. 1. Gas chromatograms of the underivatized acetone soluble fractions isolated from the pitch deposits selected for this study. $\operatorname{Ac}(n)$ : $n$-fatty alcohol series; $\operatorname{Ak}(n): n$-alkane series; $n$ denotes the total carbon atom number.

groups that are converted into methyl esters. This technique has been found especially useful for the characterization of pitch deposits made up of fatty acids salts since analyses of these moieties are biased upon conventional pyrolysis due to decarboxylation processes (del Río et al., 1998-2000). Pyrolysis (TMAH) of the residues showed a predominant release of a series of fatty acid methyl esters from all the deposits (Fig. 2), indicating that the fatty acids may exist in salt form in the pitch deposits. The distribution of the fatty acid methyl esters in the pitch deposit residues ranged from $\mathrm{C}_{14}$ to $\mathrm{C}_{26}$,

Table 1

Relative compositions (\%) of acetone extracts and residues in the pitch deposits selected for this study

\begin{tabular}{llcc}
\hline & Pitch in pulp (episode A) & Pitch in pulp (episode B) & Pitch in circuits (episode B) \\
\hline Acetone soluble fraction & 16 & 15 & 25 \\
Alkanes $\left(\mathrm{C}_{27}-\mathrm{C}_{31}\right)$ & 0.8 & 1.4 & 1.5 \\
Fatty alcohols $\left(\mathrm{C}_{22}-\mathrm{C}_{34}\right)$ & 2.2 & 3.6 & 3.5 \\
Defoamer & 13 & 10 & 20 \\
& & & 75 \\
Acetone insoluble fraction & 84 & 78 & 70 \\
Fatty acid salts $\left(\mathrm{C}_{14}-\mathrm{C}_{26}\right)$ & 12 & 7 & 5 \\
$\alpha$-Hydroxyfatty acid salts $\left(\mathrm{C}_{14}-\mathrm{C}_{24}\right)$ & 72 & 78 & \\
\hline
\end{tabular}




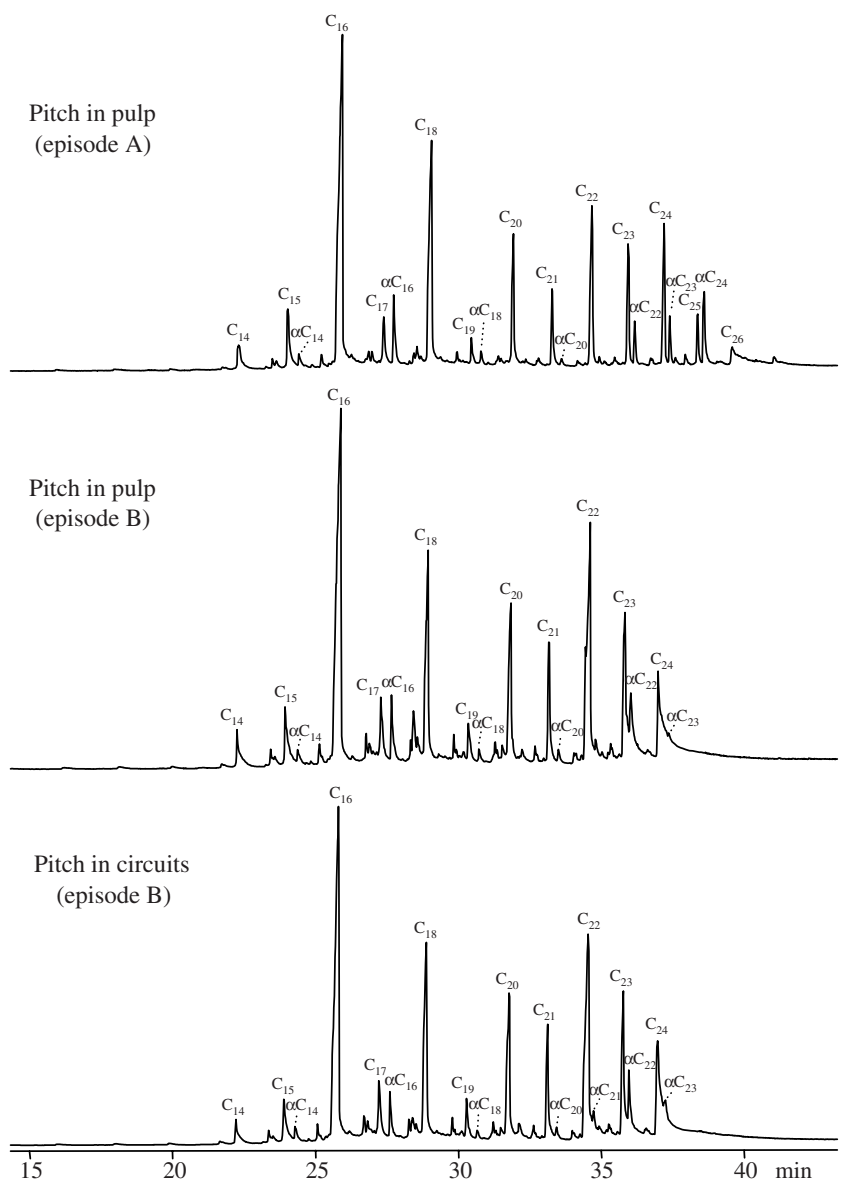

Fig. 2. Pyrolysis (TMAH) of acetone insoluble residues isolated from the pitch deposits selected for this study. $\mathrm{C}_{n}$ refers to the chain length of fatty acid methyl esters, $\alpha \mathrm{C}_{n}$ refers to the chain length of $\alpha$-methoxy fatty acid methyl esters.

with palmitic acid methyl ester $\left(\mathrm{C}_{16}\right)$ predominating. On the other hand, a series of $\alpha$-methoxy fatty acid methyl esters (from $\mathrm{C}_{14}$ to $\mathrm{C}_{24}$ ) were also identified upon Py (TMAH)-GC/MS of the residues, indicating the presence of $\alpha$-hydroxy fatty acids in the pitch deposits. Probably, the fatty acids were forming salts with calcium, ferric, aluminum or magnesium ions among others, present in the process. High amounts of these cations were found in all the pitch deposits analyzed in this work (Table 2).

\subsection{Analysis of lipophilic extractives from hemp fibers}

Since one of the main sources of pitch deposits during pulp manufacturing are the lipophilic compounds present in the raw materials, the composition of lipophilic extractives from bast fibers of industrial hemp was analyzed and compared with that of pitch deposits. The chromatogram of the underivatized lipophilic extract of hemp fibers is shown in Fig. 3 and the composition is listed in Table 3. The main compounds identified were series of fatty acids, $n$-alkanes, steroids, triterpenoids
Table 2

Abundance (ppm) of metals in the pitch deposits selected for this study (episode B)

\begin{tabular}{lcc}
\hline Metals & Pitch in pulp & Pitch in circuits \\
\hline $\mathrm{Ca}$ & 83,800 & 63,900 \\
$\mathrm{Fe}$ & 48,500 & 21,900 \\
$\mathrm{Al}$ & 21,300 & 10,200 \\
$\mathrm{Mg}$ & 17,700 & 7000 \\
$\mathrm{~K}$ & 2320 & 1490 \\
$\mathrm{Na}$ & 1870 & 1030 \\
$\mathrm{Mn}$ & 1160 & 562 \\
$\mathrm{Cr}$ & 474 & 296 \\
$\mathrm{Ni}$ & 197 & 108 \\
$\mathrm{Cu}$ & 166 & 71 \\
\hline
\end{tabular}

and waxes. Among the fatty acids $\left(\mathrm{C}_{14}-\mathrm{C}_{30}\right)$, hexadecanoic $\left(\mathrm{C}_{16}\right)$, octadecadienoic $\left(\mathrm{C}_{18: 2}\right)$, octadecenoic $\left(\mathrm{C}_{18: 1}\right)$, octadecanoic $\left(\mathrm{C}_{18}\right)$ and eicosanoic $\left(\mathrm{C}_{20}\right)$ acids predominated. Minor amounts of $\alpha$-hydroxy fatty acids $(0.2 \%)$ were also identified as TMS derivatives. The series of $n$-alkanes were identified in the range from $\mathrm{C}_{21}$ to $\mathrm{C}_{33}$, with a strong odd-over-even carbon atom predominance, nonacosane $\left(\mathrm{C}_{29}\right)$ being the most abundant. Free and esterified sterols and triterpenols were also identified in hemp fibers, sitosterol and $\beta$-amyrin being the most abundant, respectively. Waxes, consisting of a complex mixture of different long-chain fatty acids esterified to different long-chain fatty alcohols, were found in the range from $\mathrm{C}_{40}$ to $\mathrm{C}_{54}$ with a strong even-over-odd carbon atom predominance. A detailed analysis of the individual waxes by GC/MS indicated that the esterified fatty acids ranged from $\mathrm{C}_{16}$ to $\mathrm{C}_{30}$, with $\mathrm{C}_{20}$ and $\mathrm{C}_{22}$ predominating, and the esterified fatty alcohols ranged from $\mathrm{C}_{18}$ to $\mathrm{C}_{38}$ with $\mathrm{C}_{22}, \mathrm{C}_{24}, \mathrm{C}_{26}, \mathrm{C}_{28}$ and $\mathrm{C}_{30}$ predominating. Finally, minor amounts of free fatty alcohols, with docosanol $\left(\mathrm{C}_{22}\right)$, octacosanol $\left(\mathrm{C}_{28}\right)$ and triacontanol $\left(\mathrm{C}_{30}\right)$ predominating, as well as steroid hydrocarbons, steroid ketones and steryl glycosides were present. It could be observed that some of the lipophilic

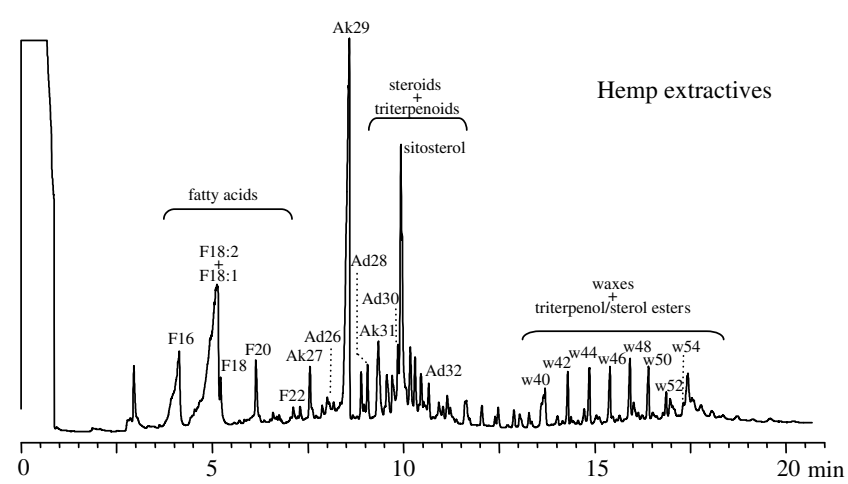

Fig. 3. Gas chromatogram of the underivatized lipophilic extract of hemp bast fibers. $\mathrm{F}(n): n$-fatty acid series; $\operatorname{Ad}(n): n$-aldehyde series; $\mathrm{Ak}(n): n$-alkane series; $\mathrm{w}(n)$ : wax series; $n$ denotes the total carbon atom number. 
Table 3

Composition (\%) of lipophilic extractives from hemp fibers

\begin{tabular}{ll}
\hline Compounds & $\%$ \\
\hline Alkanes $\left(\mathrm{C}_{21}-\mathrm{C}_{33}\right)$ & 28.7 \\
Steroid hydrocarbons & 1.7 \\
Fatty acids $\left(\mathrm{C}_{14}-\mathrm{C}_{30}\right)$ & 12.1 \\
Fatty alcohols $\left(\mathrm{C}_{18}-\mathrm{C}_{32}\right)$ & 3.3 \\
Aldehydes $\left(\mathrm{C}_{21}-\mathrm{C}_{32}\right)$ & 4.3 \\
Free sterols/triterpenols & 18.2 \\
Steroid/triterpenoid ketones & 4.5 \\
Waxes $\left(\mathrm{C}_{40}-\mathrm{C}_{54}\right)$ & 11.7 \\
Esterified sterols/triterpenols esters & 14.5 \\
Sterol glycosides & 1 \\
\hline
\end{tabular}

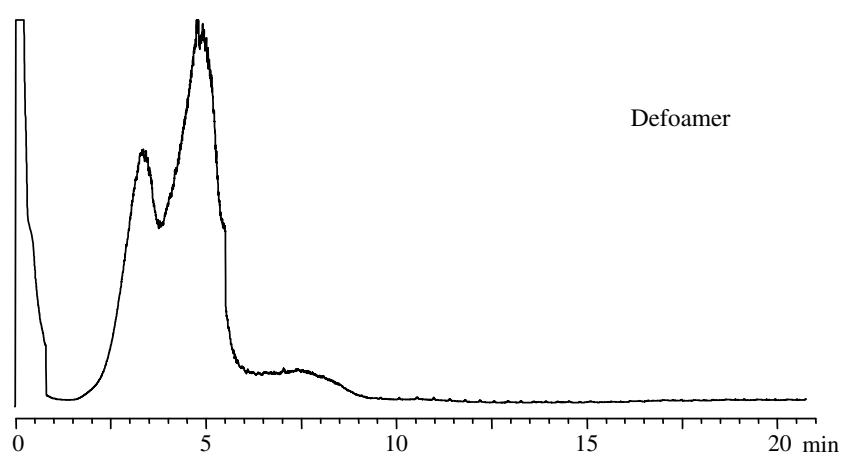

Fig. 4. Gas chromatogram of a defoamer used in the process.

extractives from hemp fibers were also present in pitch deposits indicating that these compounds survive cooking and ECF bleaching as discussed below.

\subsection{Analysis of the defoamers used in the process}

The two defoamers used in the mill when the pitch episodes occurred were also analyzed. The chromatograms of two defoamers were very similar and only one of them is shown in Fig. 4. The GC and GC/MS results revealed the presence of wide, non-resolved peaks, showing similar shape, the same retention times and identical mass fragmentation profiles to those present in the chromatograms of the acetone extracts of the pitch deposits. Therefore, the origin of these peaks in the pitch deposits has been assigned to these defoamers. The derivatization of the defoamer samples prior to the GC and GC/MS analyses did not improve the resolution of those peaks.

\section{Discussion}

The present study shows that the pitch deposits produced during high-quality paper pulp manufacturing from industrial hemp bast fibers were constituted by lipophilic extractives (mainly fatty acids) from the raw material, together with significant amounts of defoamer used in the process as outlined in Table 1. The major part of the fatty acids present in pitch deposits were forming salts with calcium, magnesium, aluminum and other cations, which could have their origin in the raw material and water as well as in the additives used in the process. Deposition of these fatty acid salts can be induced by several factors including the $\mathrm{pH}$, the ionic strength and the concentration of multivalent ions in the pulping and bleaching process. When $\mathrm{pH}$ is sufficiently high, as during alkaline cooking, the fatty acids dissociate and can dissolve in water, forming sodium soaps. Sodium soaps of fatty acids are soluble in alkali, if the ionic strength is not too high and the concentration of multivalent metal ions is not high enough to precipitate insoluble soaps. In the subsequent steps after the cooking, when the $\mathrm{pH}$ comes down, di- and trivalent metal ions present in the water will react with the carboxylate groups of the fatty acids in competition with sodium ions to produce insoluble, sticky, hard water soaps that have a tendency to deposit (Holmbom, 2000; Ström, 2000). On the other hand, it is known that excessive use of defoamers is among the most important causes of deposits and pitch problems (Allen, 2000). Although defoamers were added in different parts of the process, the pitch episodes described here seemed to be related to the addition of defoamers in the unbleached part of the mill, in the last washing steps before bleaching. Furthermore, a synergy between defoamer and hard water soap deposition seems evident. Therefore, in mills where there are conditions for the deposition of both hard water soaps $(\mathrm{pH}>6$ and presence of multivalent metal ions) and defoamer, the deposition rate is greater than the sum of the rates expected from these two factors (Allen, 2000). Significant amounts of both hard water soaps (of fatty acids coming from hemp fibers) and defoamer were found in the pitch deposits studied here.

Among the fatty acids present in the pitch deposits, the absence of unsaturated fatty acids (octadecadienoic and octadecenoic acids) that were prominent in the hemp extractives was notable. The same occurred with other unsaturated lipids that were present in significant amounts in the raw material, such as sterols (mainly sitoterol) and triterpenols, but were practically absent in the three pitch deposits analyzed. This can be explained by the ECF bleaching (with chlorine dioxide) used at the mill. Chlorine dioxide reacts with unsaturated lipophilic compounds such as unsaturated fatty acids and sterols present in hemp fibers, favoring oxidation reactions (Björklund-Jansson et al., 1995; del Río et al., 1998; Gutiérrez et al., 2001b,c; Freire et al., 2003). Chlorine dioxide reaction products are more hydrophilic than the parent compounds and are therefore easier to wash out of the pulp (Holmbom, 2000). As mentioned before, minor amounts of an oxidation product of oleic acid and two oxidized sitosterol derivatives not present in the raw material were identified in 
the pitch deposits. These compounds have been previously found during Eucalyptus kraft pulping and ECF bleaching (Freire et al., 2002, 2003). In contrast, the saturated lipids (i.e. saturated fatty acids and sterols) are more resistant to oxidation and therefore were found in the pitch deposits.

The amount of other lipophilic extractives arising from hemp fibers seemed to be comparatively lower in the pitch deposits. Among these, fatty alcohols and alkanes were stable under the soda/anthraquinone cooking and ECF bleaching. Moreover, their very low solubility in water makes them difficult to remove in the washing stages. Waxes and sterol and triterpenol esters were also identified among the lipophilic extractives from hemp fibers but these compounds were not found in the acetone extracts of the pitch deposits analyzed indicating that they were hydrolyzed during the alkaline cooking. The relatively higher abundance of fatty alcohols in the pitch deposits compared to alkanes (despite their relatively low proportion in the raw material) indicates that the fatty alcohols released in the hydrolysis of waxes accumulate in the pitch deposits. The stability of alkanes and fatty alcohols during soda/anthraquinone cooking was previously reported during the manufacturing of non-wood pulps (Gutiérrez and del Río, 2003a,b; Gutiérrez et al., 2004).

\section{Acknowledgement}

This study has been supported by the Spanish Ministerio de Ciencia y Tecnología (MCYT) and FEDER funds (projects 2FD97-0896-C02-02 and AGL200200393). A.G. acknowledges a "Ramón y Cajal" contract of the Spanish MCYT. We also thank CELESA (Tortosa, Spain) for providing the samples.

\section{References}

Allen, L.H., 2000. Pitch control in pulp mills. In: Back, E.L., Allen, L.H. (Eds.), Pitch Control, Wood Resin and Deresination. Tappi Press, Atlanta, USA, Chapter 11.

Back, E.L., Allen, L.H., 2000. Pitch Control, Wood Resin and Deresination. Tappi Press, Atlanta, USA.

Björklund-Jansson, M., Wormald, P., Dahlman, O., 1995. Reactions of wood extractives during ECF and TCF bleaching of Kraft pulp. Pulp \& Paper Canada 96, 42-45. del Río, J.C., Gutiérrez, A., González-Vila, F.J., Martín, F., Romero, J., 1998. Characterization of organic deposits produced in the kraft pulping of Eucalyptus globulus wood. J. Chromatogr. A 823, 457465.

del Río, J.C., Gutiérrez, A., González-Vila, F.J., Martín, F., 1999. Application of pyrolysis-gas chromatography-mass spectrometry to the analysis of pitch deposits and synthetic polymers in pulp and pulp mills. J. Anal. Appl. Pyrolysis 49, 165-177.

del Río, J.C., Romero, J., Gutiérrez, A., 2000. Analysis of pitch deposits produced in kraft pulp mills using totally chlorine free bleaching sequences. J. Chromatogr. A 874, 235-245.

Freire, C.S.R., Silvestre, A.J.D., Pereira, C.C.L., Pascoal Neto, C., Cavaleiro, J.A.S., 2002. New lipophilic components of pitch deposits from an Eucalyptus globulus ECF bleached kraft pulp mill. J. Wood Chem. Technol. 22 (1), 55-66.

Freire, C.S.R., Silvestre, A.J.D., Pascoal Neto, C., 2003. Oxidized derivatives of lipophilic extractives formed during hardwood kraft pulp bleaching. Holzforschung 57, 503-512.

Gutiérrez, A., del Río, J.C., González-Vila, F.J., Martín, F., 1998. Analysis of lipophilic extractives from wood and pitch deposits by solid-phase extraction and gas chromatography. J. Chromatogr. A $823,449-455$.

Gutiérrez, A., del Río, J.C., 2003a. Lipids from flax fibers and their fate in alkaline pulping. J. Agric. Food Chem. 51 (17), 4965-4971.

Gutiérrez, A., del Río, J.C., 2003b. Lipids from flax fibers and their fate in alkaline pulping. J. Agric. Food Chem. 51 (23), 6911-6914 (Addition/Correction).

Gutiérrez, A., del Río, J.C., Martínez, M.J., Martínez, A.T., 2001a. The biotechnological control of pitch in paper pulp manufacturing. Trends Biotechnol. 19 (9), 340-348.

Gutiérrez, A., Romero, J., del Río, J.C., 2001b. Lipophilic extractives from Eucalyptus globulus pulp during kraft cooking followed by TCF and ECF bleaching. Holzforschung 55, 260-264.

Gutiérrez, A., Romero, J., del Río, J.C., 2001c. Lipophilic extractives in process waters during manufacturing of totally chlorine free Kraft pulp from eucalypt wood. Chemosphere 44 (5), 1237-1242.

Gutiérrez, A., Rodríguez, I.M., del Río, J.C., 2004. Chemical characterization of lignin and lipid fractions in kenaf bast fibers used for manufacturing high-quality papers. J. Agric. Food Chem. 52 (15), 4764-4773.

Hillis, W.E., Sumimoto, M., 1989. Effect of extractives on pulping. In: Rowe, J.W. (Ed.), Natural Products of Woody Plants II. SpringerVerlag, Berlin, pp. 880-920.

Holmbom, B., 2000. Resin reactions and deresination in bleaching. In: Back, E.L., Allen, L.H. (Eds.), Pitch Control, Wood Resin and Deresination. Tappi Press, Atlanta, USA, Chapter 9.

Holton, H.H., 1977. Soda additive softwood pulping: a major new process. Pulp Paper Canada 78, T218.

Moore, G., 1996. Nonwood Fibre Applications in Papermaking. Pira International, Leatherhead, Surrey, UK.

Ström, G., 2000. Physico-chemical properties and surfactant behavior. In: Back, E.L., Allen, L.H. (Eds.), Pitch Control, Wood Resin and Deresination. Tappi Press, Atlanta, USA, Chapter 5.

Struik, P.C., Amaducci, S., Bullard, M.J., Stutterheim, N.C., Venturi, G., Cromack, H.T.H., 2000. Agronomy of fibre hemp (Cannabis sativa L.) in Europe. Ind. Crop. Prod. 11, 107-118. 